\title{
Endoscopic Treatment for Gastrointestinal Stromal Tumors in the Upper Gastrointestinal Tract
}

\author{
In Kyung Yoo and Joo Young Cho \\ Department of Gastroenterology, Cha Bundang Medical Center, Cha University College of Medicine, Seongnam, Korea
}

See "Efficacy and Safety of Endoscopic Treatment for Gastrointestinal Stromal Tumors in the Upper Gastrointestinal Tract" by Cicilia Marcella, Shakeel Sarwar, Hui Ye, et al., on page 458-465.

Gastrointestinal stromal tumors (GISTs) are the most common malignant subepithelial tumors (SETs) of the gastrointestinal tract. They originate from the intestinal cells of Cajal. Currently, the diagnosis of GISTs is based on immunohistochemical staining for c-kit protein and CD34, which are expressed in $>80 \%$ of GISTs. ${ }^{1}$ GISTs must be differentiated from other SETs because of the malignancy potential of GISTs. According to the current guidelines, surgery is recommended for gastric GISTs of $>2 \mathrm{~cm}$ in size, and endoscopic surveillance is recommended for GISTs of $<2 \mathrm{~cm}$ in size. ${ }^{2}$ However, even if the size of a GIST is small and the probability of malignancy is low, up to $3.7 \%$ of small GISTs $(<2 \mathrm{~cm})$ are reported to have a high risk or an unexpected increase in size. ${ }^{2,3}$ Furthermore, the regular surveillance strategy involves some risks, including delayed diagnosis of the malignancy of the disease, complications arising from repetitive endoscopy, and poor patient compliance. In addition, patients must bear the financial burden or emotional stress of follow-up. For patients who are reluctant to undergo surgery, endoscopic resection may be a better option than surgery. Endoscopic resection techniques have many ad-

\footnotetext{
Received: May 4, 2020 Revised: May 13, 2020

Accepted: May 13, 2020

Correspondence: Joo Young Cho

Department of Gastroenterology, Cha Bundang Medical Center, Cha University College of Medicine, 59 Yatap-ro, Bundang-gu, Seongnam 13496, Korea Tel: +82-31-780-5641, Fax: +82-32-780-5005, E-mail: cjy6695@naver.com ORCID: https://orcid.org/0000-0002-7182-5806
}

(c) This is an Open Access article distributed under the terms of the Creative Commons Attribution Non-Commercial License (http://creativecommons.org/ licenses/by-nc/3.0) which permits unrestricted non-commercial use, distribution, and reproduction in any medium, provided the original work is properly cited. vantages to surgery, such as shorter operative time, lower cost, less intraoperative bleeding, and improved quality of life. In addition, they show favorable outcomes. ${ }^{4,5}$

In this issue of Clinical Endoscopy, Marcella et al. introduced endoscopic submucosal dissection (ESD), endoscopic full-thickness resection (EFTR), and submucosal tunneling endoscopic resection (STER) as endoscopic methods for removing GISTs, with favorable outcomes. ${ }^{6}$ Endoscopic treatment (ET) attained a $100 \%$ en bloc resection rate, $77.4 \%$ complete resection rate, and $8.3 \%$ complication rate. Eight patients in the ESD group showed apparent adverse events such as intraoperative perforation $(n=7)$ and massive bleeding $(n=1)$. Most patients were managed with endoscopic repair. Only one patient underwent emergency laparoscopic surgery for a large tumor that was tightly adhered to the third layer.

Endoscopic resection of GISTs is superior in some aspects such as having good accessibility to the cardia or esophagogastric junction, which are technically difficult to approach using the laparoscopic method. ${ }^{5}$ Moreover, surgery is sometimes challenging when localizing an intracavitary tumor. However, it is preferred for the resection of larger tumors and achieves a sufficient negative resection margin. ${ }^{6}$

In this issue of Clinical Endoscopy, Marcella et al. ${ }^{6}$ indicated that ET is a feasible and favorable alternative option for surgery for GISTs even if they are large $(3$ cases, $>5 \mathrm{~cm}$ included). However, the resection of large GISTs using ET remains controversial, and no consensus has been reached. ${ }^{7,8}$ Minimal complication risk with optimal endoscopic choice is important, and the treatment may be decided on the basis of the surgeon's preference and experience and patient/tumor characteristics. 
Between the endoscopic procedures, several different features must be considered regarding implementation. ESD is the most common and standard ET for gastric SETs. Submucosal injection and dissection are performed to ensure complete resection. Owing to advanced instruments and high experience of endoscopists, meticulous dissection could be performed without complications. However, for tumors originating in the deep muscularis propria layer, the risk of complications such as perforation and bleeding is increased.

EFTR is feasible when a tumor originates in the deep layer and shows a predominantly extraluminal growth. This method is similar to ESD, and the only differences are the generation of iatrogenic perforation and the closure of the gastric wall defect using clips or surgery. This invasive technique requires advanced endoscopic skills.

STER, which was reported by $\mathrm{Xu}$ et al., ${ }^{9}$ has benefits in maintaining mucosal integrity and enabling effective closure of the mucosal defect. Regarding the submucosal space, the best locations for STER are relatively straight and tubular structures such as the esophagus or gastric cardia. ${ }^{10}$

In this study, the authors demonstrated that ET is safe and feasible for GISTs. ET showed high en bloc and R0 resection rates with low complication and recurrence rates. Therefore, ET for GISTs is available as an option for patients without metastases. Additional studies with a larger cohort and prospective design are needed to verify the primary results of this study.

Conflicts of Interest

The authors have no financial conflicts of interest.
ORCID

In Kyung Yoo: https://orcid.org/0000-0003-0909-339X

\section{REFERENCES}

1. Miettinen M, Sobin LH, Lasota J. Gastrointestinal stromal tumors of the stomach: a clinicopathologic, immunohistochemical, and molecular genetic study of 1765 cases with long-term follow-up. Am J Surg Pathol 2005;29:52-68.

2. Jeong IH, Kim JH, Lee SR, et al. Minimally invasive treatment of gastric gastrointestinal stromal tumors: laparoscopic and endoscopic approach. Surg Laparosc Endosc Percutan Tech 2012;22:244-250.

3. Kim MY, Jung HY, Choi KD, et al. Natural history of asymptomatic small gastric subepithelial tumors. J Clin Gastroenterol 2011;45:330-336.

4. Abe N, Takeuchi H, Ohki A, Hashimoto Y, Mori T, Sugiyama M. Comparison between endoscopic and laparoscopic removal of gastric submucosal tumor. Dig Endosc 2018;30(Suppl 1):7-16.

5. Joo MK, Park JJ, Kim H, et al. Endoscopic versus surgical resection of GI stromal tumors in the upper GI tract. Gastrointest Endosc 2016;83:318326.

6. Marcella C, Sarwar S, Ye H, Shi RH. Efficacy and safety of endoscopic treatment for gastrointestinal stromal tumors in the upper gastrointestinal tract. Clin Endosc 2020;53:458-465.

7. Chen K, Pan Y, Zhai ST, et al. Short-term outcomes of laparoscopic local resection for gastric submucosal tumors: a single-center experience of 266 patients. BMC Surg 2017;17:33.

8. Choi CI, Lee SH, Hwang SH, et al. Various features of laparoscopic tailored resection for gastric submucosal tumors: a single institution's results for 168 patients. Surg Endosc 2016;30:1450-1458.

9. Xu MD, Cai MY, Zhou PH, et al. Submucosal tunneling endoscopic resection: a new technique for treating upper GI submucosal tumors originating from the muscularis propria layer (with videos). Gastrointest Endosc 2012;75:195-199.

10. Yamada M, Saito Y, Mojtahed A. Minimally invasive endoscopic surgery for complex colorectal lesions: progress from standard treatments to full thickness resections. Ann Laparosc Endosc Surg 2018;3:56. 